Dementia

and Geriatric

Cognitive Disorders
Dement Geriatr Cogn Disord 2017;44:129-143

DOI: $10.1159 / 000478007$

(C) 2017 The Author(s)

Accepted: June 5, $2017 \quad$ Published by S. Karger AG, Basel

Published online: August 5, 2017 www.karger.com/dem

This article is licensed under the Creative Commons Attribution-NonCommercial-NoDerivatives 4.0 International License (CC BY-NC-ND) (http://www.karger.com/Services/OpenAccessLicense). Usage and distribu-

tion for commercial purposes as well as any distribution of modified material requires written permission.

\title{
Effectiveness of Florbetapir PET Imaging in Changing Patient Management
}

\author{
Michael J. Pontecorvo ${ }^{a}$ Andrew Siderowf $^{a}$ Bruno Dubois ${ }^{b}$ \\ P. Murali Doraiswamy c Giovanni B. Frisonid, e Michael Grundman ${ }^{\mathrm{f}} \mathrm{g}$ \\ Flavio Nobilih Carl H. Sadowsky ${ }^{i}$ Stephen Salloway ${ }^{j} \quad$ Anupa K. Arora ${ }^{a}$ \\ Antoine Chevrette ${ }^{a}$ Walter Deberdtk Grazia Dell'Agnello' \\ Matthew Flitter ${ }^{a} \quad$ Nick Galante ${ }^{a}$ Mark J. Lowrey ${ }^{a}$ Ming Lu ${ }^{a}$ \\ Anne McGeehan ${ }^{a}$ Michael D. Devous Sr. ${ }^{a}$ Mark A. Mintun ${ }^{a}$ \\ ${ }^{a}$ Avid Radiopharmaceuticals (a wholly owned subsidiary of Eli Lilly and Company), \\ Philadelphia, PA, USA; ${ }^{b}$ Dementia Research Center (IM2A), Institut du Cerveau et de la \\ Moelle épinière (ICM), UMR-S975, Université Pierre et Marie Curie-Paris 6, AP-HP, Hôpital \\ de la Salpêtrière, Paris, France; ${ }^{\circ}$ Department of Psychiatry, Duke University Health System \\ and the Duke Institute for Brain Sciences, Durham, NC, USA; Departments of ${ }^{\mathrm{d}}$ Psychiatry

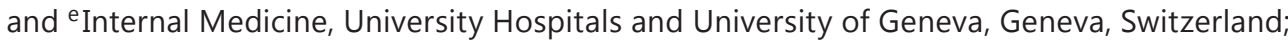 \\ ${ }^{f}$ Global R\&D Partners, LLC, and 9 University of California, San Diego, CA, USA; ${ }^{\text {h Clinical }}$ \\ Neurology, Department of Neuroscience (DINOGMI), University of Genoa, Genoa, Italy;

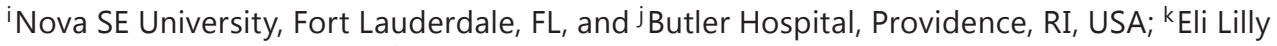 \\ Benelux, Brussels, Belgium; 'Lilly Italia, Sesto Fiorentino, Italy
}

\section{Keywords}

Alzheimer disease · Amyloid · Diagnosis - Differential diagnosis · Florbetapir

\begin{abstract}
Aims: To evaluate the impact of amyloid PET imaging on diagnosis and patient management in a multicenter, randomized, controlled study. Methods: Physicians identified patients seeking a diagnosis for mild cognitive impairment or dementia, possibly due to Alzheimer disease $(A D)$, and recorded a working diagnosis and a management plan. The patients underwent florbetapir PET scanning and were randomized to either immediate or delayed (1-year) feedback regarding amyloid status. At the 3-month visit, the physician updated the diagnosis and recorded a summary of the actual patient management since the post-scan visit. The study
\end{abstract}

The trial is registered at ClinicalTrials.gov (NCT\# 01703702).

Michael J. Pontecorvo, PhD

Avid Radiopharmaceuticals (a wholly owned subsidiary of Eli Lilly and Company)

3711 Market Street

Philadelphia, PA 19104 (USA)

E-Mail pontecorvo @ avidrp.com 
Pontecorvo et al.: Effectiveness of Florbetapir PET Imaging in Changing Patient Management

examined the impact of immediate versus delayed feedback on patient diagnosis/management at 3 and 12 months. Results: A total of 618 subjects were randomized (1:1) to immediate or delayed feedback arms, and 602 subjects completed the 3-month primary endpoint visit. A higher proportion of patients in the immediate feedback arm showed a change in diagnosis compared to the controls ( 32.6 vs. $6.4 \% ; p=0.0001$ ). Similarly, a higher proportion of patients receiving immediate feedback had a change in management plan (68 vs. $55.5 \%$; $p<0.002$ ), mainly driven by changes in AD medication. Specifically, acetylcholinesterase inhibitors were prescribed to $67 \%$ of the amyloid-positive and $27 \%$ of the amyloid-negative subjects in the information group compared with 56 and 43\%, respectively, in the control group ( $p<0.0001$ ). These between-group differences persisted until the 12-month visit. Conclusion: Knowledge of the amyloid status affects the diagnosis and alters patient management.

(C) 2017 The Author(s)

Published by S. Karger AG, Basel

\section{Introduction}

The diagnostic algorithm for Alzheimer disease (AD) has traditionally been based on identification of patients with a core clinical syndrome, especially memory impairment, plus exclusion of alternate potential etiologies based on MRI and laboratory tests [1]. However, a number of alternative conditions including advanced age [2], geriatric depression, and slowly progressive medial temporal pathology [3-5] can cause an amnestic syndrome that can be confused with mild AD. Conversely, AD pathology may not always result in an amnestic phenotype [6]. Consequently, a clinical diagnosis of AD is reported to be only $70-80 \%$ accurate by comparison to neuropathological examination, and up to $20 \%$ of clinically diagnosed AD patients do not have AD pathology at autopsy $[7,8]$.

Biomarkers may provide a useful adjunct to a comprehensive clinical examination, helping to identify pathologies that may contribute to the cognitive impairment [9-12]. The development of PET (positron emission tomography) imaging biomarkers that bind to fibrillar $\beta$-amyloid $(\mathrm{A} \beta)$, including Pittsburgh compound B $\left({ }^{11} \mathrm{C}-\mathrm{PiB}\right)[13]$, florbetaben $\left({ }^{18} \mathrm{~F}\right)$ [14], flutemetamol $\left({ }^{18} \mathrm{~F}\right)[15]$, and florbetapir $\left({ }^{18} \mathrm{~F}\right)[16,17]$, has made it possible to estimate whether or not a given patient has moderate-to-frequent neuritic amyloid plaques, a required feature for the pathological diagnosis of AD. At least five groups have now begun exploring the potential impact of amyloid PET imaging biomarkers on diagnosis and management in a clinical setting [18-25]. These studies have consistently reported that knowledge of the A $\beta$ status could change the diagnosis in the direction of the scan result, improve physicians' confidence in their diagnosis, and change treatment. However, these studies have been limited in various ways. In some cases, physicians were asked retrospectively how the scan results did, or might have, changed the diagnosis and management, rather than prospectively assessing a management plan prior to and after the scan information [22, 23]. In other studies, physicians reported management plans prior to and after receiving the scan results, but a follow-up was not conducted to determine what diagnostic tests and medications the patients actually received [19]. Simultaneous unblinding to $A \beta$ status and other biomarker data (e.g., FDG) also confounds the interpretation of several studies [21, 22]. Most important, none of these studies included a control group to prospectively evaluate how physicians actually diagnosed and managed similar patients in the absence of amyloid imaging information.

The current study is therefore the first prospective, randomized, controlled multicenter study to evaluate the impact of amyloid imaging on diagnosis and management in patients with cognitive impairment suspected to be related to AD. 
Pontecorvo et al.: Effectiveness of Florbetapir PET Imaging in Changing Patient Management

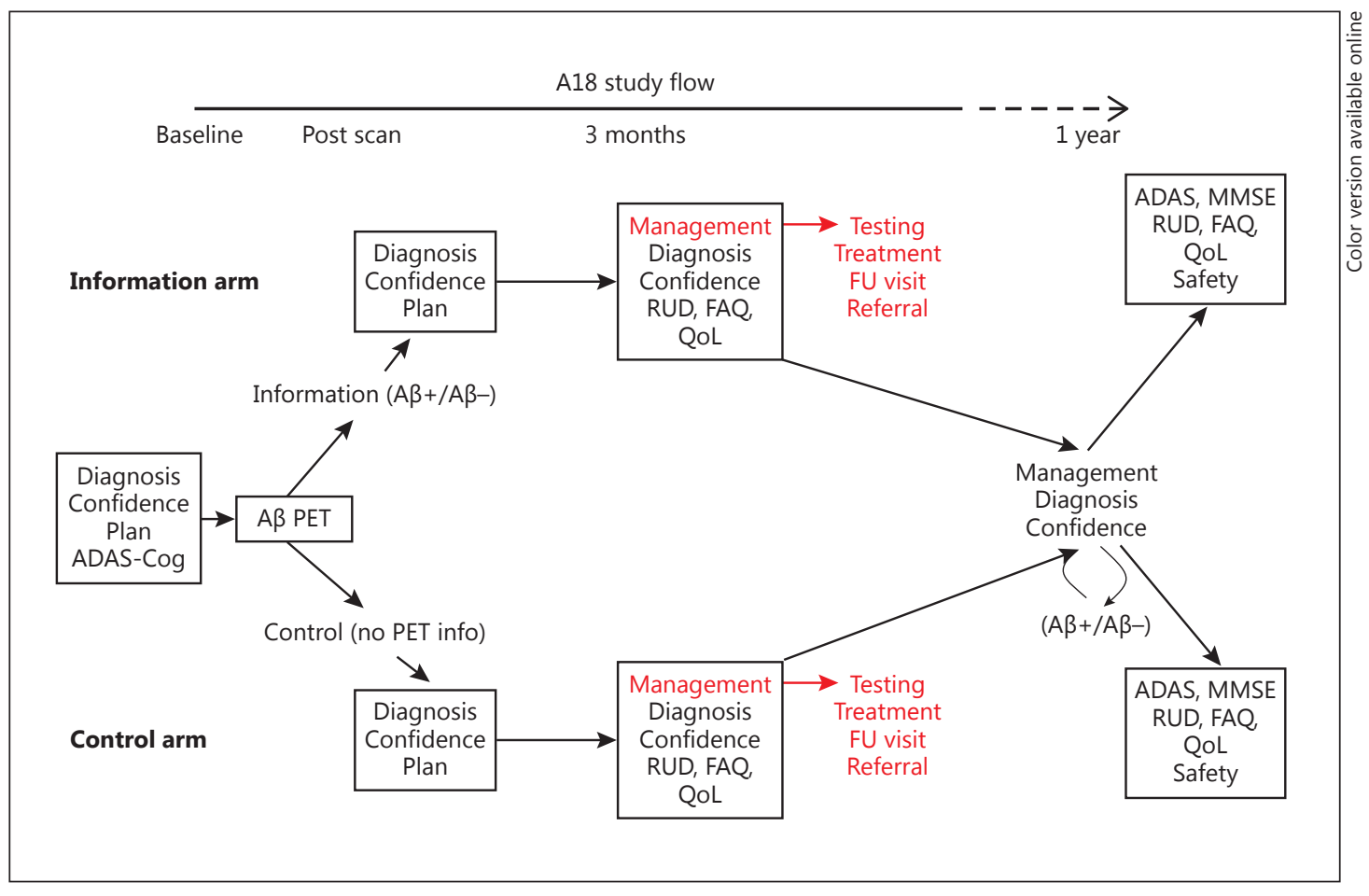

Fig. 1. Study design. A18 study design and flow. FU, follow-up.

\section{Subjects and Methods}

\section{Participants}

This study was conducted at a total of 60 centers in France, Italy, and the USA and included 618 patients, 50-90 years of age, with evidence for late-life progressive cognitive decline (mild cognitive impairment [MCI] or dementia with an MMSE score $\geq 16$ ) for whom the cause of the impairment was uncertain ( $<85 \%$ certain), but a diagnosis of $\mathrm{AD}$ was considered possible ( $\geq 15 \%$ likely). All patients had either completed a diagnostic evaluation for cognitive decline within 18 months prior to enrollment, or were currently undergoing evaluation. Patients currently undergoing evaluation were to be enrolled in the study at a point when the treating physician judged that amyloid imaging would be clinically appropriate. All patients had a study partner who consented to participate as an informant.

A patient was excluded from enrollment if the patient or physician knew the result of a previous amyloid scan; if the patient had a known brain lesion, pathology, or alternative diagnosis that strongly explained the patient's clinical presentation; if the patient had a current serious or unstable illness or a life expectancy $<1$ year; or if the patient had previously participated in an experimental study with an amyloid-targeting agent (e.g., anti-amyloid immunotherapy, $\gamma$-secretase or $\beta$-secretase inhibitor). Additionally, patients were excluded if they were under the care of the physician exclusively for the purposes of a trial; patients were only enrolled if they were referred, walk-in patients, or existing patients of the physician/practice, such that the physician/practice took primary responsibility for management of the cognitive deficit over the course of the trial. Neither the patients nor the physicians were formally required to meet the appropriate use criteria [26]. However, similar to a previous study [27], the patients and physicians met the spirit of the criteria in that there was $\geq 15 \%$ uncertainty regarding the patient diagnosis/etiology, and the principal investigators/institutions were predominantly experienced in AD research and included neurologists, psychiatrists, and geriatricians who had a range of clinical experience.

This protocol was approved by the relevant ethics committees and regulatory authorities. The study procedures and risks were explained in advance, and written informed consent was given by the patient or a legally authorized representative. 
Dementia

Cognitive Disorders

\begin{tabular}{l|l}
\hline Dement Geriatr Cogn Disord 2017;44:129-143 \\
\hline DOI: 10.1159/000478007 & $\begin{array}{l}\text { C 2017 S. Karger AG, Basel } \\
\text { www.karger.com/dem }\end{array}$ \\
\hline
\end{tabular}

Pontecorvo et al.: Effectiveness of Florbetapir PET Imaging in Changing Patient Management

Procedures

Figure 1 shows the design of this study. The physicians and patients were made aware of the controlled study design, but they were not aware beforehand which group (information/control) the patient would be randomized to. Upon enrollment of a patient, the treating physician completed a diagnostic worksheet, providing

- a working diagnosis,

- a degree of certainty for that diagnosis,

- a diagnostic testing plan including plans for any additional laboratory, imaging, or neuropsychological tests, or plans for referral to other specialists for diagnostic testing, and

- a management plan including plans for changes in AD medications, changes in other medications with the goal of management of cognitive impairment (e.g., dose changes for beta blockers), plans for referral to a clinical trial, or plans for a follow-up visit for reevaluation.

The patients/informants then completed a battery of study-specific tests assessing cognition (ADAS-Cog, MMSE) and function (Functional Activities Questionnaire [FAQ]), as well as mood, anxiety, and quality of life (GDS, GAD-7, QoL-AD, EQ-5D, Resource Utilization in Dementia instrument, Zarit Burden Interview, and SelfEfficacy Scale). These study-specific tests were not used in the diagnostic process, and the ADAS was completed with an independent rater, blinded to other clinical and diagnostic results. The treating physician was blinded to the ADAS results, unless the ADAS was otherwise part of the standard of care at that center. No additional diagnostic testing was to be performed until after the florbetapir PET amyloid imaging visit.

Within 30 days of completing the baseline evaluation, the subjects underwent amyloid PET imaging. A 10-min PET acquisition (2 frames of $5 \mathrm{~min}$ ) was conducted $50 \mathrm{~min}$ after administration of $370 \mathrm{MBq}$ florbetapir $\left({ }^{18} \mathrm{~F}\right)$. The PET data were reconstructed with an iterative or row-action maximum likelihood algorithm with an image size of a $128 \times 128$ or $200 \times 200$ matrix, a pixel size of $2-2.67 \times 2-2.67 \mathrm{~mm}$, a slice thickness of 2-4.25 mm, and a post-reconstruction gaussian filter of 3-5 mm or a relaxation parameter of a normal or sharp filter, then interpreted as either amyloid positive $(A \beta+)$ or amyloid negative $(A \beta-)$ by a central reader. The patients were then randomized to have their treating physician informed of the PET amyloid status either immediately (information condition) or at the end of the study, 1 year later (control condition). Upon receiving (or not receiving) the PET scan results, the physicians again completed the diagnostic worksheet, providing a working diagnosis, the degree of certainty for that diagnosis, a diagnostic testing plan, and a management plan, and proceeded to manage the patient without study restrictions for a period of 3 months.

Approximately 3 months after the baseline visit, the patient and their study partner returned to the clinic. The treating physician reviewed the patient's medical record and recorded the actual status of diagnosis and management of the patient in the 3 months since the baseline visit, including the actual diagnosis and confidence level at the time of the 3-month visit, additional diagnostic tests performed since the baseline visit, any $\mathrm{AD}$ medications actually prescribed, changes in other medications implemented with the goal of management of cognitive impairment (e.g., dose changes for beta blockers), referrals made to a clinical trial, and follow-up visits actually conducted for diagnostic reevaluation. The patient and the informant then completed the same battery of functional and quality-of-life tests performed at baseline (except for the ADAS).

The patient and the informant returned again to the clinic for a final visit 1 year after the baseline assessments. Prior to this visit, and prior to receiving the amyloid PET results for the patients in the control group (delayed information), the physician reviewed the medical record and again recorded the actual diagnosis and management of the patient. The cognitive, functional, and quality-of-life assessments were repeated at the final visit, and the physicians were allowed to discuss the amyloid PET results with those patients who had not previously received them and to devise modified treatment plans if necessary.

\section{Statistical Analyses}

The primary objective of this study was to determine whether knowledge of the florbetapir PET amyloid status altered patient management, and specifically whether the proportion of patients with a change in a predefined composite of management items would be significantly greater in the information group than in the control group. For the purpose of this analysis, the composite was considered positive if the actual management in the 3 months after scanning reflected a change from the physician's pre-scan (baseline) management plan for any of the following patient management options:

1. Major diagnostic tests, e.g., structural imaging (brain CT or MRI), lumbar puncture, FDG-PET, SPECT, and genetic testing 
Dementia

Cognitive Disorders

Table 1. Baseline demographics of the study population

\begin{tabular}{l|l}
\hline \multicolumn{2}{l}{ Dement Geriatr Cogn Disord 2017;44:129-143 } \\
\hline DOI: 10.1159/000478007 & $\begin{array}{l}\text { C 2017 S. Karger AG, Basel } \\
\text { www.karger.com/dem }\end{array}$ \\
\hline
\end{tabular}

Pontecorvo et al.: Effectiveness of Florbetapir PET Imaging in Changing Patient Management

\begin{tabular}{|c|c|c|c|}
\hline & $\begin{array}{l}\text { Information } \\
\text { group } \\
(n=308)\end{array}$ & $\begin{array}{l}\text { Control } \\
\text { group } \\
(n=310)\end{array}$ & $\begin{array}{l}\text { Total } \\
(n=618)\end{array}$ \\
\hline \multicolumn{4}{|l|}{ Country } \\
\hline France & $87(28.2)$ & $87(28.1)$ & $174(28.2)$ \\
\hline Italy & $109(35.4)$ & $112(36.1)$ & 221 (35.8) \\
\hline USA & $112(36.4)$ & $111(35.8)$ & 223 (36.1) \\
\hline Age, years & $73.1 \pm 8.2$ & $72.7 \pm 7.94$ & $72.9 \pm 8.07$ \\
\hline Female & $142(46.1)$ & $160(51.6)$ & 302 (48.9) \\
\hline \multicolumn{4}{|l|}{ Race $^{\mathrm{a}}$} \\
\hline African-American & $4(1.3)$ & $2(0.6)$ & $6(1.0)$ \\
\hline Caucasian & $214(69.5)$ & $220(71.0)$ & $434(70.2)$ \\
\hline Other & $3(1.0)$ & $1(0.3)$ & $4(0.6)$ \\
\hline Education, years ${ }^{\mathrm{b}}$ & $12.0 \pm 4.2$ & $11.8 \pm 4.3$ & $12.1 \pm 4.21$ \\
\hline$A \beta+$ & $192(62.3)$ & $201(64.8)$ & $393(63.6)$ \\
\hline ADAS-Cog score & $15.9 \pm 8.18$ & $16.1 \pm 9.12$ & $16.0 \pm 8.66$ \\
\hline MMSE score & $24.0 \pm 3.63$ & $23.9 \pm 3.98$ & $23.9 \pm 3.80$ \\
\hline \multicolumn{4}{|l|}{ Cognitive status } \\
\hline MCI & $171(55.5)$ & $171(55.2)$ & 342 (55.3) \\
\hline Dementia & $137(44.5)$ & $139(44.8)$ & $276(44.7)$ \\
\hline
\end{tabular}

Values are presented as the mean \pm SD or $n(\%) . A \beta$, amyloid beta; MCI, mild cognitive impairment. ${ }^{a}$ Regulations in France do not allow collecting information on race. ${ }^{\mathrm{b}}$ Educational years derived as the following: "elementary school" = 6, "middle school" = 8, "high school" = 12 , "college/university" = 16, "postgraduate" = 20, "other" $=12.4$.

2. Initiation or cessation of AD medications, or initiation or cessation of other medications/treatments, with the intent of improving cognition

3. Neuropsychological testing that was conducted outside the clinical interview setting and involved either referral to a specialist or $>2$ neuropsychological tests

4. Physician follow-up for diagnostic reevaluation of cognitive impairment (visits conducted for routine patient monitoring, and visits conducted in response to a change in health status or further decline, were recorded as health outcomes, but they were not included in the composite)

5. Referral to a specialist for further evaluation and treatment of the underlying cause of the patient's cognitive decline (e.g., referral to a psychiatrist for evaluation of depressive or psychotic symptoms)

A Pearson $\chi^{2}$ test was used to test whether the difference in the proportion of subjects with a change in management from the baseline plan to the actual management 3 months after baseline between the information and the control arm was statistically significant.

Planned secondary analyses similarly analyzed between-group differences in change of individual items and subcomponents of the primary management composite, as well as changes in counseling and referral to support groups over the 3 months after baseline and again at the 12-month time point. Between-group differences in change in diagnosis and change in diagnostic confidence were evaluated at 3 and 12 months using Pearson's $\chi^{2}$ test, and mixed model repeated measures adjusted for confounding factors for diagnosis and for confidence, respectively.

Exploratory analyses also compared changes in health outcomes, quality of life, and psychometric test results from baseline to month 12 in the information and control groups using mixed model repeated measures adjusted for confounding factors, as well as Fisher's exact test to assess the individual categories of the EQ-5D. Logistic regression with a generalized estimating equation to account for within-subject correlations was conducted to compare changes in the planned prescription of acetylcholinesterase inhibitors (AChE-I) from baseline to the 3- and 12-month follow-ups between the study arms by amyloid status.

The primary analysis population for all analyses included all patients with evaluable data at the relevant time point. However, subgroup analyses were also conducted to separately evaluate trends in the three countries, and, where appropriate, in amyloid-positive versus amyloid-negative subjects. 
Pontecorvo et al.: Effectiveness of Florbetapir PET Imaging in Changing Patient Management

Table 2. Detailed baseline diagnoses

\begin{tabular}{|c|c|c|c|c|c|c|}
\hline & \multicolumn{2}{|l|}{ All $(n=618)$} & \multicolumn{2}{|c|}{ Information group $(n=308)$} & \multicolumn{2}{|c|}{ Control group $(n=310)$} \\
\hline & $\begin{array}{l}\mathrm{A} \beta+ \\
(n=393)\end{array}$ & $\begin{array}{l}\mathrm{A} \beta- \\
(n=225)\end{array}$ & $\begin{array}{l}\mathrm{A} \beta+ \\
(n=192)\end{array}$ & $\begin{array}{l}\mathrm{A} \beta- \\
(n=116)\end{array}$ & $\begin{array}{l}\mathrm{A} \beta+ \\
(n=201)\end{array}$ & $\begin{array}{l}\mathrm{A} \beta- \\
(n=109)\end{array}$ \\
\hline AD total & $326(83.0)$ & $138(61.3)$ & $158(82.3)$ & $67(57.8)$ & $168(83.6)$ & $71(65.1)$ \\
\hline \multicolumn{7}{|l|}{ Typical AD or dementia of the } \\
\hline Alzheimer type & $199(50.6)$ & $79(35.1)$ & $96(50.0)$ & $38(32.8)$ & $103(51.2)$ & $41(37.6)$ \\
\hline Mixed dementia with $\mathrm{AD}$ & $34(8.7)$ & $22(9.8)$ & $19(9.9)$ & $12(10.3)$ & $15(7.5)$ & $10(9.2)$ \\
\hline Lewy body variant of $\mathrm{AD}$ & $7(1.8)$ & $20(0.9)$ & $3(1.6)$ & $1(0.9)$ & $4(2.0)$ & $1(0.9)$ \\
\hline Atypical AD & $86(21.9)$ & $35(15.6)$ & $40(20.8)$ & $16(13.8)$ & $46(22.9)$ & $19(17.4)$ \\
\hline Indeterminate total & $17(4.3)$ & $26(11.6)$ & $8(4.2)$ & $14(12.1)$ & $9(4.5)$ & $12(11.0)$ \\
\hline Non-AD total & $50(12.7)$ & $61(27.1)$ & $26(13.5)$ & $35(30.2)$ & $24(11.9)$ & $26(23.9)$ \\
\hline Vascular etiology & $4(1.0)$ & $8(3.6)$ & $2(1.0)$ & $7(6.0)$ & $2(1.0)$ & $1(0.9)$ \\
\hline Structural lesions ${ }^{\mathrm{a}}$ & $2(0.5)$ & $1(0.4)$ & $2(1.0)$ & $0(0.0)$ & $0(0.0)$ & $1(0.9)$ \\
\hline Other, please specify & $6(1.5)$ & $2(0.9)$ & $4(2.1)$ & $1(0.9)$ & $2(1.0)$ & $1(0.9)$ \\
\hline Not $A D$, but etiology uncertain & $13(3.3)$ & $11(4.9)$ & $5(2.6)$ & $7(6.0)$ & $8(4.0)$ & $4(3.7)$ \\
\hline Mixed etiology without AD & $2(0.5)$ & $4(1.8)$ & $1(0.5)$ & $0(0.0)$ & $1(0.5)$ & $4(3.7)$ \\
\hline Medication induced $^{\mathrm{b}}$ & $1(0.3)$ & $2(0.9)$ & $0(0.0)$ & $2(1.7)$ & $1(0.5)$ & $0(0.0)$ \\
\hline Lewy body disease & $4(1.0)$ & $2(0.9)$ & $2(1.0)$ & $1(0.9)$ & $2(1.0)$ & $1(0.9)$ \\
\hline Frontotemporal disease & $9(2.3)$ & $19(8.4)$ & $5(2.6)$ & $11(9.5)$ & $4(2.0)$ & $8(7.3)$ \\
\hline Depression/anxiety/psychosis & $9(2.3)$ & $11(4.8)$ & $5(2.6)$ & $6(5.2)$ & $4(2.0)$ & $5(4.6)$ \\
\hline Alcohol-related impairment & $0(0.0)$ & $1(0.4)$ & $0(0.0)$ & $0(0.0)$ & $0(0.0)$ & $1(0.9)$ \\
\hline
\end{tabular}

Values are presented as $n(\%)$. The bold figures in parentheses per column add up to $100 \%$. The detailed baseline diagnoses shown in this table were made by physicians prior to receiving the florbetapir PET scan results. The diagnoses were retroactively grouped according to amyloid status within the study arms. A $\beta$, amyloid beta; AD, Alzheimer disease. ${ }^{a}$ Brain tumor, hydrocephalus, brain trauma, etc. ${ }^{\mathrm{b}}$ Anticholinergics, antidepressants, antianxiety medications, narcotics, etc.

Finally, the 12-month follow-up period also provided an opportunity to evaluate the progression of cognitive change in amyloid-positive and amyloid-negative subjects, independent of whether or not the investigator/subject received information regarding the scan interpretation $(A \beta+/ A \beta-)$. Demented and MCI patients were examined separately. The primary analysis compared the change from baseline ADAS-Cog score in $A \beta+$ versus $A \beta-M C I$ subjects, with baseline ADAS-Cog score and age as covariates.

\section{Results}

Table 1 shows the demographics of the patients enrolled. There were no significant demographic differences between the subjects in the information group and those in the control group. A slightly greater proportion of patients were enrolled in the USA and Italy than in France. The average patient age was 72.9 years, and $63.6 \%$ of the patients were amyloid positive by PET scan. Table 2 details the baseline (pre-scan) diagnoses. There was no significant difference in the distribution of diagnoses between the information and the control group. Online supplemental Table S1 (for all online suppl. material, see www. karger.com/doi/10.1159/000478007) provides historical information about the prior workup of the patients (i.e., before the study) with regard to major diagnostic tests (e.g., structural imaging, FDG-PET, CSF, etc.). These tests were generally balanced between the two groups. Prior structural imaging (CT or MRI) was completed for a majority of the patients (control group: 80.9\%; information group: 81.3\%). Interestingly, CSF and FDG-PET data were available for up to 20.0 and $27.0 \%$ of the patients, respectively; yet the investigators still expressed uncertainty in the diagnosis and entered the subjects in this study to receive 
Pontecorvo et al.: Effectiveness of Florbetapir PET Imaging in Changing Patient Management

Table 3. Shift in diagnostic category from baseline to 3 months

\begin{tabular}{|c|c|c|c|c|}
\hline & \multirow[t]{2}{*}{ Subjects, $n$} & \multicolumn{3}{|c|}{ Post-scan diagnosis (at 3 months) } \\
\hline & & due to $\mathrm{AD}$ & indeterminate & not due to $\mathrm{AD}$ \\
\hline Control group, $A \beta+$ & 194 & & & \\
\hline Due to AD & 164 & $159(97.0)$ & 0 & $5(3.0)$ \\
\hline Indeterminate & 8 & $3(37.5)$ & $5(62.5)$ & 0 \\
\hline Not due to AD & 22 & $1(4.6)$ & 0 & $21(95.5)$ \\
\hline Information group, $A \beta+$ & 188 & & & \\
\hline Due to $\mathrm{AD}$ & 155 & $152(98.1)$ & $1(0.6)$ & $2(1.3)$ \\
\hline Indeterminate & 8 & $7(87.5)$ & $1(12.5)$ & 0 \\
\hline Not due to AD & 25 & $23(92.0)$ & $1(4.0)$ & $1(4.0)$ \\
\hline Control group, $A \beta-$ & 105 & & & \\
\hline Due to $\mathrm{AD}$ & 67 & $62(92.5)$ & $1(1.5)$ & $4(6.0)$ \\
\hline Indeterminate & 12 & $1(8.3)$ & $8(66.7)$ & $3(25.0)$ \\
\hline Not due to AD & 26 & $1(3.8)$ & 0 & $25(96.2)$ \\
\hline Information group, $A \beta-$ & 113 & & & \\
\hline Due to $\mathrm{AD}$ & 65 & $11(16.9)$ & $1(1.5)$ & $53(81.5)$ \\
\hline Indeterminate & 13 & 0 & $3(23.1)$ & $10(76.9)$ \\
\hline Not due to AD & 35 & 0 & 0 & $35(100)$ \\
\hline
\end{tabular}

Values are presented as $n(\%)$. The pre-scan diagnostic categories are shown on the left and the new diagnostic categories at 3 months are shown in the columns.

amyloid PET scans. In both the information and the control condition, the proportion of amyloid-positive PET scans was higher among patients classified as having impairment due to AD than among patients thought to have a non-AD etiology of impairment.

Tables 3 and 4 summarize the changes (shifts) in diagnoses from baseline to the 3 - and 12 -month visits, respectively. The diagnoses in the information group changed in a direction consistent with the scan result that had been reported to the physician. Thus, for example, the month 3 diagnosis was changed to an AD etiology for 23/25 (92.0\%) amyloid-positive subjects initially diagnosed as non-AD, and to a non-AD etiology for 53/65 (81.5\%) amyloid-negative subjects initially diagnosed as having an impairment due to AD. In contrast, the month 3 diagnoses in the control group were largely unchanged from the baseline diagnoses. Thus, $21 / 22$ (95.5\%) amyloid-positive control patients initially diagnosed as non-AD and 62/67 (92.5\%) amyloid-negative control patients initially diagnosed with an etiology due to AD retained the same diagnosis at the 3-month visit. Overall, a significantly higher proportion of the patients who received immediate feedback regarding their amyloid status showed a change in diagnosis $(98 / 301$ [32.6\%] vs. $19 / 299$ [6.4\%]; $p=0.0001)$. Moreover, these trends were not altered by continued follow-up. At the time of the 1-year visit, the initial working diagnosis remained unchanged for $>92 \%$ of the subjects in the control group. Regardless of amyloid positivity, there was a significant difference between the information and the control group's changed diagnosis status among patients whose clinical diagnosis was not predicted by the amyloid PET scan $(p<0.0001)$.

The amyloid PET results also altered diagnostic confidence. Across amyloid-positive and -negative subjects there was a $20 \%$ increase in diagnostic confidence in the information group versus a $1 \%$ increase in the control group $(p<0.001)$ at the month 3 visit, an effect that persisted for up to 1 year (Table 5). Additionally, the exploratory analyses at the end of the study after the amyloid scan information had been released to the control group at 12 months 
Pontecorvo et al.: Effectiveness of Florbetapir PET Imaging in Changing Patient Management

Table 4. Shift in diagnostic category from baseline to 12 months

\begin{tabular}{|c|c|c|c|c|}
\hline & \multirow[t]{2}{*}{ Subjects, $n$} & \multicolumn{3}{|c|}{ Post-scan diagnosis (12 months) } \\
\hline & & due to $\mathrm{AD}$ & indeterminate & not due to $\mathrm{AD}$ \\
\hline Control group, $A \beta+$ & 191 & & & \\
\hline Due to $\mathrm{AD}$ & 162 & 157 (96.9) & 0 & $5(3.0)$ \\
\hline Indeterminate & 8 & $4(50.0)$ & $4(50.0)$ & 0 \\
\hline Not due to $\mathrm{AD}$ & 21 & $2(4.6)$ & 0 & $19(90.5)$ \\
\hline Information group, $A \beta+$ & 174 & & & \\
\hline Due to $\mathrm{AD}$ & 143 & $142(99.3)$ & 0 & $1(0.7)$ \\
\hline Indeterminate & 7 & $6(85.7)$ & $1(14.3)$ & 0 \\
\hline Not due to $\mathrm{AD}$ & 24 & $21(87.5)$ & $1(4.2)$ & $2(8.3)$ \\
\hline Control group, $\mathrm{A} \beta-$ & 103 & & & \\
\hline Due to $\mathrm{AD}$ & 66 & $58(87.9)$ & $2(3.0)$ & $6(9.0)$ \\
\hline Indeterminate & 12 & $1(8.3)$ & $8(66.7)$ & $3(25.0)$ \\
\hline Not due to $\mathrm{AD}$ & 25 & $1(4.0)$ & 0 & $24(96.0)$ \\
\hline Information group, $A \beta-$ & 108 & & & \\
\hline Due to $\mathrm{AD}$ & 61 & $10(16.4)$ & $1(1.6)$ & $50(82.0)$ \\
\hline Indeterminate & 13 & $1(7.7)$ & $3(23.1)$ & $9(69.2)$ \\
\hline Not due to $\mathrm{AD}$ & 34 & 0 & $1(2.9)$ & $33(97)$ \\
\hline
\end{tabular}

Values are presented as $n(\%)$. The pre-scan diagnostic categories are shown on the left and the shift in diagnostic category at 12 months is shown in the columns.

Table 5. Diagnostic confidence

\begin{tabular}{llllll}
\hline Visit & Study arm & Subjects, $n$ & Baseline & $\begin{array}{l}\text { LS mean change } \\
\text { from baseline, } \\
\text { estimate }\end{array}$ & $\begin{array}{l}\text { Change in } \\
\text { information vs. } \\
\text { control, } p \text { value }\end{array}$ \\
\hline Month 3 & Information & 277 & $66.2(0.63)$ & $20.210(0.868)$ & $<0.001^{*}$ \\
& Control & 278 & $66.4(0.61)$ & $1.202(0.859)$ & \\
\hline Month 12 & Information & 259 & $66.1(0.65)$ & $20.970(0.885)$ & $<0.001^{*}$ \\
& Control & 272 & $66.4(0.62)$ & $2.233(0.863)$ & \\
\hline
\end{tabular}

Values are presented as the mean (SE) unless specified otherwise. LS, least squares. * Indicates statistical significance at the 0.05 level.

showed changes in diagnosis (in a direction consistent with the scan) and increased diagnostic confidence in a manner similar to what was seen for the information group.

These between-group differences in diagnostic change were accompanied by group differences in the probability of change in management relative to the initial plan (the a priori primary outcome variable). The actual patient management as recorded at month 3 differed from the planned management recorded at baseline in $\geq 1$ of the items in the composite index for 204 of 300 subjects (68.0\%) in the information group versus 166 of 299 subjects (55.5\%) in the control group (odds ratio: 1.70; $p<0.002$; Table 6; see online suppl. Tables S2, S3 for greater detail). When controlled for potential confounding factors such as cognitive status (MCI/dementia), country, and florbetapir $\left({ }^{18} \mathrm{~F}\right)$ PET scan result $(A \beta+/ A \beta-)$, the composite result did not change; the information arm had 1.77 times higher odds $(p=0.001)$ of having a change in patient management than the controls. 
Pontecorvo et al.: Effectiveness of Florbetapir PET Imaging in Changing Patient Management

Table 6. Primary endpoint (change at 3 months)

\begin{tabular}{lccrr}
\hline & Information group & Control group & Odds ratio (95\% CI) & $p$ value \\
\hline Patient management composite & $68(204 / 300)$ & $55.5(166 / 299)$ & $1.70(1.22-2.38)$ & $<0.002$ \\
AD medication (AChE-I, mem., other) & $35.7(107 / 300)$ & $22.1(66 / 299)$ & $1.96(1.36-2.81)$ & $<0.001$ \\
Referral to specialist & $30.7(90 / 300)$ & $23.4(70 / 299)$ & $1.45(1.01-2.08)$ & 0.046 \\
Neuropsychological testing & $14.7(44 / 300)$ & $9.7(29 / 299)$ & $1.60(0.97-2.64)$ & 0.063 \\
Physician follow-up for reevaluation & $15(45 / 300)$ & $14.1(42 / 299)$ & $1.08(0.69-1.70)$ & 0.741 \\
Major diagnostic tests & $21(63 / 300)$ & $20.4(61 / 299)$ & $1.04(0.70-1.54)$ & 0.856 \\
\hline
\end{tabular}

Percentages of patients calculated relative to the total number of patients in the analysis population with evaluable data. $p$ value: Pearson's $\chi^{2}$ test. AD, Alzheimer disease; AChE-I, acetylcholinesterase inhibitors; mem., memantine.

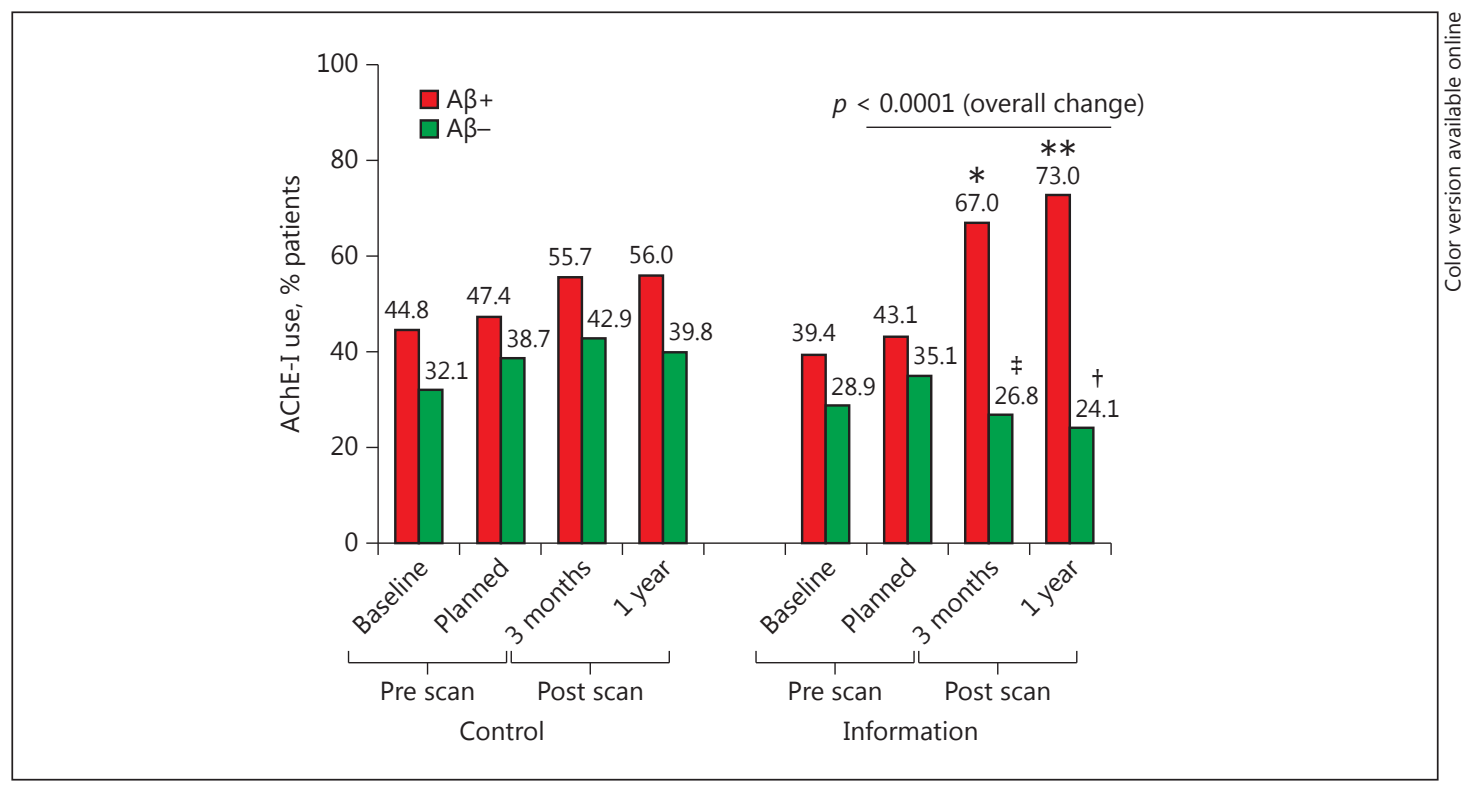

Fig. 2. Impact of amyloid PET information on prescription of AChE-I. $p$ values from the logistic regression model with generalized estimating equations; $p<0.0001$ for overall interaction of amyloid status, study arm, and visit. Change in medication use from baseline to 3 months and from baseline to 1 year was significantly greater for the information group than for the control group as indicated by the following symbols: ${ }^{* *} p<$ $0.0001 ;{ }^{*} p<0.001 ;{ }^{\ddagger} p<0.01 ;^{\dagger} p<0.05$. AChE-I use is shown as a percentage of patients at the following time points: pre scan baseline (actual use), pre scan physician-recorded planned use, post scan 3 months (actual use), and post scan 12 months (actual use). A $\beta$, amyloid beta; AChE-I, acetylcholinesterase inhibitor.

Table 6 shows that among the management composite items, changes in AD medication showed the greatest differences between the information and the control group (35.7 vs. 22.1\%; odds ratio: 1.96; $p<0.001$ ). The AD medication component in the management composite included changes in AChE-I (donepezil, rivastigmine, and galantamine), memantine, and other medications that were changed in the hope of improving cognition (e.g., modification of doses of blood pressure medications). To try to further understand these changes, we looked selectively at the prescription of AChE-I, because these are likely the first agents prescribed following an AD diagnosis (as opposed to memantine, which is usually added on later). Figure 2 shows that relative to either actual use of AChE-I at baseline or the planned 
Pontecorvo et al.: Effectiveness of Florbetapir PET Imaging in Changing Patient Management

use as recorded in the pre-scan management plan, use of AChE-I in the information group changed in a direction consistent with the scan result; thus, in the information group, prescription of AChE-I at 3 months after baseline had increased from a planned $43 \%$ to an actual $67 \%$ among the $A \beta+$ patients, but had decreased from a planned $35 \%$ to an actual $27 \%$ among the $A \beta$ - patients. In contrast, in the control group AChE-I use increased relative to the baseline plan regardless of the amyloid status (Fig. 2). Moreover, these trends were not altered by continued follow-up; the differences in AChE-I use between the information and the control group were, if anything, greater 1 year than 3 months after baseline.

In contrast to the $\mathrm{AD}$ medication item, there were no significant differences between the information and the control group in major diagnostic test results or conduct of reevaluation visits. In both the information and the control group, the majority of change between the pre-scan plan and the actual result came about because the planned diagnostic tests and follow-up visits were not included in the post-scan plan and were not conducted within the 3-month follow-up period.

Although not a prespecified objective due to lack of power, this study also provided an opportunity to look for trends with respect to the impact of information on cognitive or health outcomes at the 1-year time point. No significant benefit was observed for the information group relative to the control group with reference to cognitive change from baseline as assessed by the ADAS, MMSE, or FAQ or to quality of life as assessed by the QoL-AD, Caregiver Self-Efficacy Scale, EQ-5D, and Zarit Burden Interview.

Progression of cognitive change was also evaluated in amyloid-positive and amyloidnegative subjects, independent of whether or not the investigator/subject received information regarding the scan interpretation. Overall, there were no significant differences in the progression of cognitive change as assessed by change from the baseline ADAS-Cog score between $\mathrm{A} \beta+$ and $\mathrm{A} \beta-\mathrm{MCI}(p=0.568)$ or $\mathrm{AD}$ subjects $(p=0.763)$.

Finally, florbetapir was well tolerated, and there was no evidence of an increased risk associated with informing a patient of the amyloid status. The most common adverse events reported in the $48 \mathrm{~h}$ following PET scanning were headache $(2.8 \%)$, nausea $(0.6 \%)$, asthenia $(0.5 \%)$, and fatigue $(0.5 \%)$. No other event was reported by $>1$ subject. One suicide attempt was reported, but this event occurred 10 months after scanning in an MCI patient randomized to the control arm and whose medical history was significant for cardiovascular disease, reoccurrence of leukemia, and depression.

With a few exceptions, the trends in the individual countries were generally similar to those reported for the study as a whole. There were no significant differences in demographics across the countries, except that the subjects in Italy were less well educated and had higher (worse) ADAS-Cog scores at baseline than those in France, and especially the USA, whether viewed overall or separately for mildly impaired and demented patients (online suppl. Table S4).

The classification of cases across diagnoses was generally consistent across the countries, with the exception that US physicians were more likely to use the classifications "indeterminate etiology" or "non-AD but etiology uncertain" (supplemental Tables S5-S7). Additionally, within the AD category, Italian physicians were more likely to enroll patients with a pre-scan working diagnosis of typical AD (although the etiology was $<85 \%$ certain). Interestingly, despite the higher mean ADAS scores, the proportion of patients classified as demented was not higher in Italy than in the other countries, suggesting Italian physicians may assign a diagnosis of dementia at a later disease stage than do physicians in the other countries. Regardless of these minor differences, all three countries showed a change in diagnosis in the direction of the scan result in the information but not in the control group (online suppl. Tables S5-S7).

The numerical trends for changes in the management plan within countries were also similar to those for the study as a whole, but with lower statistical reliability, in part due to 
Pontecorvo et al.: Effectiveness of Florbetapir PET Imaging in Changing Patient Management

smaller sample sizes. The examination of AChE-I use across the countries did show some subtle differences that may reflect differences in the practice of medicine (online suppl. Fig. S1). Specifically, prescription of AChE-I at baseline was lower in France than in the other countries, and it was particularly high in the USA. All three countries showed an increase in prescriptions in the $A \beta+$ subjects and a decrease or no change in the $A \beta$ - subjects of the information group relative to planned use at baseline. However, whereas the prescription of AD medications in the control group stayed relatively close to planned treatment in the USA and Italy, the prescription of AD medications in France increased compared to the relatively low baseline/planned use (online suppl. Fig. S1).

\section{Discussion}

This study found that the proportion of patients with a change in management from baseline to 3 months for a predefined management composite was significantly greater in the information group than in the control group. The analysis of individual items in the management composite suggested that the difference between the information and the control group was driven largely by the AD treatment component. It is important to note that while the changes in $\mathrm{AD}$ medication in the control group simply reflected increased prescription of AChE-I, the AD medication changes in the information group were in a direction consistent with the scan results and were paralleled by a change in diagnosis. Additionally, physician confidence in their diagnosis at the 3-month visit was significantly higher in the information group than in the control group $(p<0.001)$.

The difference between the information and the control group with respect to the management composite met the study's primary success criteria. The percentage of patients in the information group with changes in the management composite was consistent with the results of previous noncontrolled studies [19]. However, in this study, the percentage of subjects with management changes in the control group was larger than might have been expected. The analysis of individual components of the management composite suggests that these changes were largely driven by changes from planned diagnostic laboratory and neuropsychological testing. In both the information and the control group, regardless of amyloid status, the proportion of patients completing new diagnostic laboratory or neuropsychological tests within the 3-month follow-up window was lower than the proportion of patients for whom these tests were planned at baseline. In many cases, the change was apparent at the post-scan visit and the 3-month visit. This result may reflect the particular design of this study, in that the physicians may have been initially inclined to schedule additional testing in the absence of availability of amyloid PET (per the pre-scan plan); however, once the scan was performed, the physicians may have opted for watchful waiting, knowing that the scan result would eventually be available at the end of the study.

In contrast to the testing component, the AD medication component changed in a direction consistent with the scan result in the information group but not in the control group. These effects were driven almost entirely by differences in prescription of AChE-I, such as donepezil, with little or no effect seen on prescription of memantine or other medications that might incidentally contribute to or alleviate cognitive impairment (e.g., beta-blockers). This was expected, since, at present, AChE-I are the first medications prescribed in response to an AD diagnosis, and the treatment should be most responsive to information such as amyloid status that changes the diagnosis. Importantly, the differences between the information and the control group's use of AChE-I grew, if anything, between 3 months and 1 year, suggesting that 3 months might have been too short a time to measure the full impact of knowing the amyloid status. 
Pontecorvo et al.: Effectiveness of Florbetapir PET Imaging in Changing Patient Management

On the other hand, knowledge of the scan result did not fully determine patient treatment. In the information group, $27 \%$ of the $A \beta$ - subjects remained on AChE-I despite knowledge of the negative scan result. Although lower than the planned use (35\%), this is approximately the same percentage that was treated at baseline. These results probably reflect a willingness to treat some patients with a symptomatic therapy that could have a nonspecific cognitionenhancing effect even in nonamyloid/non-AD dementias [28-31], or an unwillingness to withdraw a previously prescribed therapy.

Together these results suggest that knowledge of the amyloid status can have an important effect on treatment management, even when only symptomatic treatments (not directed at the core disease pathology) are available. It is reasonable to speculate that knowledge of the amyloid status would have a greater impact on the prescribed use of amyloid-directed diseasemodifying therapies, thereby avoiding potentially unnecessary prescriptions for $A \beta$-patients.

The above changes in AD medication prescription in the information group paralleled the changes in clinical diagnosis. Consistent with a prior study [19], in the information group, $92 \%$ of the $A \beta+$ patients considered to have non-AD-related impairment before the scan were diagnosed with impairment due to $\mathrm{AD}$ after the scan, and, conversely, $82 \%$ of the $\mathrm{A} \beta$ - patients considered to have impairment due to $\mathrm{AD}$ before the scan were diagnosed with non-AD impairments after the scan. In the present study there was a relatively infrequent use of the "indeterminate" classification for patients with an $A \beta$ - scan result who were initially diagnosed with impairment due to AD, compared with the previous study that offered the same etiologic classification options (1.5\% in the present study vs. $66.7 \%$ in the study by Grundman et al. [19]). This most likely resulted from clearer instructions given the investigators, specifically that the indeterminate classification should be used to indicate that it is not possible to choose between $\mathrm{AD}$ and non-AD etiology as opposed to indicating that the investigator cannot assign a specific etiology to the impairment (i.e., non-AD NOS).

Importantly, knowledge of the amyloid status led to between-group (information vs. control) differences in diagnosis and treatment, with an impact that persisted for 12 months. These results also indicate that in the absence of PET scan information, physicians did not improve their understanding of the etiology of the impairment by following the patients for a period of up to 1 year.

No significant benefit was observed for the information group relative to the control group with reference to cognitive or functional change from baseline. Note, however, that these analyses were exploratory and post hoc; the protocol was neither designed nor powered for these evaluations. As with any diagnostic test, amyloid imaging is conducted in the context of other diagnostic procedures, and is expected to primarily benefit patients who would not have otherwise received the correct diagnosis - and particularly those who would not otherwise have received AChE-I therapy for AD. Considering the short duration of follow-up (1 year) and the fact that it is necessary to account for heterogeneity in disease etiology, amyloid status, level of severity (MCI/dementia), and previous/ongoing therapy, the potential subset of subjects with an expected benefit is too small for meaningful evaluation taken alone, and constitutes too small a percentage of the overall study population, to lead to betweengroup (information vs. control) differences.

The present study also provided the opportunity to evaluate the prognostic implications of an amyloid scan, independent of the value of the scan feedback. Previous studies had shown that amyloid-positive MCI patients with an AD-like presentation deteriorated significantly faster than amyloid-negative patients over a period of 18 months to 3 years [32]. The second primary analysis in the present study tested whether this pattern would be true for MCI patients with an uncertain etiology. There was no significant difference in 1-year change from the baseline ADAS score in the overall population, although a trend $(p<0.07)$ in the expected direction was obtained in the US population. 
The lack of a difference in cognitive outcome between the $A \beta+$ and the $A \beta$ - group in the present study may be partly due to the relatively short duration of follow-up, but may also reflect the variability across countries in the population enrolled. In particular the MCI subjects in the Italian cohort (where A $\beta$ - MCI subjects showed more rapid cognitive deterioration on the ADAS) were less well educated in years and more impaired at baseline (online suppl. Table S4) than the MCI subjects in the USA (where A $\beta$ - MCI subjects showed minimal cognitive deterioration). This raises the possibility that in the USA, MCI patients were entered into the trial as having an uncertain diagnosis not because they had a complicated presentation, but because they were very early in the disease and thus difficult to diagnose. In a population with an uncomplicated presentation, an $\mathrm{A} \beta$-scan may predict a slowly progressive impairment due, for example, to aging/primary age-related tauopathy [33]. In contrast, MCI patients in Italy were likely more advanced in the disease and were being enrolled almost entirely at tertiary centers, and thus their uncertain diagnosis may have come from a more complex presentation (despite working diagnoses that frequently included AD). In such patients, a negative amyloid scan may reflect the presence of another non-AD progressive neurodegenerative disorder.

Finally, this study evaluated the potential risks of informing the patient of the amyloid status. There were no significant between-group differences in depression or anxiety symptoms, treatment-emergent adverse events or serious adverse events, psychotropic drug use or psychiatric events, or other medical events over the course of the trial beyond the treatment window. One suicide attempt was reported, but this event occurred in a patient randomized to the control group and whose medical history was significant for leukemia, cardiovascular disease, and depression.

In conclusion, this was the first randomized, controlled, prospective study to look at the impact of amyloid imaging on diagnosis as well as actual patient management and outcomes. Physicians' access to PET scan results changed the diagnosis in a direction consistent with the scan. The changes in patient management were greater in the information group, which immediately received the amyloid PET scan results, than in the control group. The group difference in management composite outcome was driven by changes in AD medication, particularly in AChE-I use, in a direction consistent with the scan. There were no group differences in cognitive performance or health outcomes at 1 year. There was no evidence that being randomized to the information group was associated with increased safety risk.

\section{Disclosure Statement}

M.J.P., A.S., A.K.A., A.C., W.D., M.F., N.G., M.J.L., M.L., A.M., M.D.D., and M.A.M. are employees of Avid (a wholly owned subsidiary of Eli Lilly and Company). G.D. is an employee of Eli Lilly and Company, the makers of Amyvid ${ }^{\circledR}$ (Florbetapir $\left({ }^{18}\right.$ F)). B.D. has received consulting fees from Eli Lilly and Company; P.M.D. has received research grants and advisory fees from several companies, and received a grant (through Duke) from Avid for this study. P.M.D. also owns shares in several health companies whose products are not discussed here. F.N. has received fees from Eli Lilly and Company (2014-2015 as a teacher in reading courses on florbetapir PET scan interpretation). Outside of this work, C.H.S. has served on advisory boards (Cognoptix, Neuronetrix) and in a speaker's bureau (Lilly) and participated in clinical research trials (Abbot, ADNI, Avanir, AVID, En Vivo, GE, Pfizer, Neuronetrix, Roche, ADCS, Neuronix Ltd., and Lilly). G.B.F. received research support/grants from the Alzheimer Forum, ASSM, Avid/Lilly, Biogen, GE International, Guerbet, IFRAD Suisse, Ixico, Merz, Nestlé, Novartis, Piramal, Roche, Siemens, Teva Pharma, Vifor Pharma, and the Alzheimer's Association. G.B.F. also was a speaker for AstraZeneca, Elan, GE, Lilly, Lundbeck, Pfizer, and TauRx and is a stakeholder of CEREBRO Sarl. M.G. previously served as a consultant to Avid. S.S. receives research support and consultancy fees from Lilly, Biogen, Merck, Genentech, and Roche. He also receives research support from Avid, Novartis, and Functional Neuromodulation. 
Pontecorvo et al.: Effectiveness of Florbetapir PET Imaging in Changing Patient Management

\section{Author Contributions}

M.J.P., A.S., A.K.A., A.C., W.D., M.F., N.G., M.L., A.M., M.G., M.D.D., and M.A.M. contributed to the conception and design of the study data acquisition and analysis/interpretation of the data. A.C., W.D., M.F., M.J.L., G.D., B.D., P.M.D., F.N., C.H.S., G.B.F., and S.S. contributed to the conduct of the study and made substantial intellectual contributions to drafting of the manuscript or figures. All authors approved the final version of the manuscript.

\section{References}

1 McKhann GM, Knopman DS, Chertkow H, Hyman BT, Jack CR Jr, Kawas CH, Klunk WE, Koroshetz WJ, Manly JJ, Mayeux R, Mohs RC, Morris JC, Rossor MN, Scheltens P, Carrillo MC, Thies B, Weintraub S, Phelps CH: The diagnosis of dementia due to Alzheimer's disease: recommendations from the National Institute on AgingAlzheimer's Association workgroups on diagnostic guidelines for Alzheimer's disease. Alzheimers Dement 2011;7:263-269.

2 Kawas CH, Kim RC, Sonnen JA, Bullain SS, Trieu T, Corrada MM: Multiple pathologies are common and related to dementia in the oldest-old: the 90+ Study. Neurology 2015;85:535-542.

3 Murray ME, Graff-Radford NR, Ross OA, Petersen RC, Duara R, Dickson DW: Neuropathologically defined subtypes of Alzheimer's disease with distinct clinical characteristics: a retrospective study. Lancet Neurol 2011;10:785-796.

4 Lewis J, Dickson DW, Lin WL, Chisholm L, Corral A, Jones G, Yen SH, Sahara N, Skipper L, Yager D, Eckman C, Hardy J, Hutton M, McGowan E: Enhanced neurofibrillary degeneration in transgenic mice expressing mutant tau and APP. Science 2001;293:1487-1491.

5 Bolmont T, Clavaguera F, Meyer-Luehmann M, Herzig MC, Radde R, Staufenbiel M, Lewis J, Hutton M, Tolnay $\mathrm{M}$, Jucker M: Induction of tau pathology by intracerebral infusion of amyloid- $\beta$-containing brain extract and by amyloid- $\beta$ deposition in APP $\times$ tau transgenic mice. Am J Pathol 2007;171:2012-2020.

6 Rabinovici GD, Ossenkoppele R, Perrotin A, Dore V, Jagust W, Bouwman FH, Joie RL, Villemagne VL, Miller B, Van der Flier WM, de La Sayette V, Masters CL, Scheltens P, Berckel BV, Rowe CC, Chetelat G: Clinically diagnosed probable AD cases with a negative amyloid PET scan: clinical findings. Alzheimers Dement 2014; 10(suppl):P12.

7 Beach TG, Monsell SE, Phillips LE, Kukull W: Accuracy of the clinical diagnosis of Alzheimer disease at National Institute on Aging Alzheimer Disease Centers, 2005-2010. J Neuropathol Exp Neurol 2012;71:266-273.

8 Serrano-Pozo A, Qian J, Monsell SE, Blacker D, Gómez-Isla T, Betensky RA, Growdon JH, Johnson KA, Frosch MP, Sperling RA, Hyman BT: Mild to moderate Alzheimer dementia with insufficient neuropathological changes. Ann Neurol 2014;75:597-601.

9 Sperling RA, Aisen PS, Beckett LA, Bennett DA, Craft S, Fagan AM, Iwatsubo T, Jack CR Jr, Kaye J, Montine TJ, Park DC, Reiman EM, Rowe CC, Siemers E, Stern Y, Yaffe K, Carrillo MC, Thies B, Morrison-Bogorad M, Wagster MV, Phelps CH: Toward defining the preclinical stages of Alzheimer's disease: recommendations from the National Institute on Aging-Alzheimer's Association workgroups on diagnostic guidelines for Alzheimer's disease. Alzheimers Dement 2011;7:280-292.

10 Dubois B, Feldman HH, Jacova C, Hampel H, Molinuevo JL, Blennow K, DeKosky ST, Gauthier S, Selkoe D, Bateman R, Cappa S, Crutch S, Engelborghs S, Frisoni GB, Fox NC, Galasko D, Habert MO, Jicha GA, Nordberg A, Pasquier F, Rabinovici G, Robert P, Rowe C, Salloway S, Sarazin M, Epelbaum S, de Souza LC, Vellas B, Visser PJ, Schneider L, Stern Y, Scheltens P, Cummings JL: Advancing research diagnostic criteria for Alzheimer's disease: the IWG-2 criteria. Lancet Neurol 2014;13:614-629.

11 Johnson KA, Minoshima S, Bohnen NI, Donohoe KJ, Foster NL, Herscovitch P, Karlawish JH, Rowe CC, Hedrick S, Pappas V, Carrillo MC, Hartley DM, Hedrick S, Pappas V, Thies WH; Alzheimer's Association; Society of Nuclear Medicine and Molecular Imaging; Amyloid Imaging Taskforce: Appropriate use criteria for amyloid PET: a report of the Amyloid Imaging Task Force, the Society of Nuclear Medicine and Molecular Imaging, and the Alzheimer's Association. Alzheimers Dement 2013; 9:e-1-e-16.

12 Johnson KA, Minoshima S, Bohnen NI, Donohoe KJ, Foster NL, Herscovitch P, Karlawish JH, Rowe CC, Hedrick S, Pappas V, Carrillo MC, Hartley DM, Hedrick S, Pappas V, Thies WH: Appropriate use criteria for amyloid PET: a report of the Amyloid Imaging Task Force, the Society of Nuclear Medicine and Molecular Imaging, and the Alzheimer's Association. J Nucl Med 2013;54:476-490.

13 Klunk WE, Engler H, Nordberg A, Wang Y, Blomqvist G, Holt DP, Bergström M, Savitcheva I, Huang GF, Estrada S, Ausén B, Debnath ML, Barletta J, Price JC, Sandell J, Lopresti BJ, Wall A, Koivisto P, Antoni G, Mathis CA, Långström B: Imaging brain amyloid in Alzheimer's disease with Pittsburgh Compound-B. Ann Neurol 2004;55: 306-319.

14 Rowe CC, Ackerman U, Browne W, Mulligan R, Pike KL, O'Keefe G, Tochon-Danguy H, Chan G, Berlangieri SU, Jones G, Dickinson-Rowe KL, Kung HP, Zhang W, Kung MP, Skovronsky D, Dyrks T, Holl G, Krause S, Friebe M, Lehman L, Lindemann S, Dinkelborg LM, Masters CL, Villemagne VL: Imaging of amyloid $\beta$ in Alzheimer's disease with ${ }^{18} \mathrm{~F}-\mathrm{BAY} 94-9172$, a novel PET tracer: proof of mechanism. Lancet Neurol 2008;7:129-135. 
Pontecorvo et al.: Effectiveness of Florbetapir PET Imaging in Changing Patient Management

15 Nelissen N, Van Laere K, Thurfjell L, Owenius R, Vandenbulcke M, Koole M, Bormans G, Brooks DJ, Vandenberghe R: Phase 1 study of the Pittsburgh compound B derivative ${ }^{18} \mathrm{~F}$-flutemetamol in healthy volunteers and patients with probable Alzheimer disease. J Nucl Med 2009;50:1251-1259.

16 Wong DF, Rosenberg PB, Zhou Y, Kumar A, Raymont V, Ravert HT, Wong DF, Rosenberg PB, Zhou Y, Kumar A, Raymont V, Ravert HT, Dannals RF, Nandi A, Brasić JR, Ye W, Hilton J, Lyketsos C, Kung HF, Joshi AD, Skovronsky DM, Pontecorvo MJ: In vivo imaging of amyloid deposition in Alzheimer disease using the radioligand ${ }^{18}$ F-AV-45 (florbetapir [corrected] F 18). J Nucl Med 2010;51:913-920.

17 Joshi AD, Pontecorvo MJ, Clark CM, Carpenter AP, Jennings DL, Sadowsky CH, Adler LP, Kovnat KD, Seibyl JP, Arora A, Saha K, Burns JD, Lowrey MJ, Mintun MA, Skovronsky DM; Florbetapir F 18 Study Investigators: Performance characteristics of amyloid PET with florbetapir F 18 in patients with Alzheimer's disease and cognitively normal subjects. J Nucl Med 2012;53:378-384.

18 Frederiksen KS, Hasselbalch SG, Hejl AM, Højgaard L, Waldemar G: Added diagnostic value of ${ }^{11} \mathrm{C}-\mathrm{PiB}-\mathrm{PET}$ in memory clinic patients with uncertain diagnosis. Dement Geriatr Cogn Disord Extra 2012;2:610-621.

19 Grundman M, Pontecorvo MJ, Salloway SP, Doraiswamy PM, Fleisher AS, Sadowsky CH, Nair AK, Siderowf A, Lu M, Arora AK, Agbulos A, Flitter ML, Krautkramer MJ, Sarsour K, Skovronsky DM, Mintun MA; 45-A17 Study Group: Potential impact of amyloid imaging on diagnosis and intended management in patients with progressive cognitive decline. Alzheimer Dis Assoc Disord 2013;27:4-15.

20 Mitsis EM, Bender HA, Kostakoglu L, Machac J, Martin J, Woehr JL, Sewell MC, Aloysi A, Goldstein MA, Li C, Sano $\mathrm{M}$, Gandy S: A consecutive case series experience with $\left[{ }^{18} \mathrm{~F}\right]$ florbetapir PET imaging in an urban dementia center: impact on quality of life, decision making, and disposition. Mol Neurodegener 2014;9:10.

21 Ossenkoppele R, Prins ND, Pijnenburg YA, Lemstra AW, van der Flier WM, Adriaanse SF, Windhorst AD, Handels RL, Wolfs CA, Aalten P, Verhey FR, Verbeek MM, van Buchem MA, Hoekstra OS, Lammertsma AA, Scheltens P, van Berckel BN: Impact of molecular imaging on the diagnostic process in a memory clinic. Alzheimers Dement 2013;9:414-421.

22 Sánchez-Juan P, Ghosh PM, Hagen J, Gesierich B, Henry M, Grinberg LT, O’Neil JP, Janabi M, Huang EJ, Trojanowski JQ, Vinters HV, Gorno-Tempini M, Seeley WW, Boxer AL, Rosen HJ, Kramer JH, Miller BL, Jagust WJ, Rabinovici GD: Practical utility of amyloid and FDG-PET in an academic dementia center. Neurology 2014; 82:230-238.

23 Schipke CG, Peters O, Heuser I, Grimmer T, Sabbagh MN, Sabri O, Hock C, Kunz M, Kuhlmann J, Reininger C, Blankenburg M: Impact of beta-amyloid-specific florbetaben PET imaging on confidence in early diagnosis of Alzheimer's disease. Dement Geriatr Cogn Disord 2012;33:416-422.

24 Zwan MD, Bouwman FH, Konijnenberg E, van der Flier WM, Lammertsma AA, Verhey FR, Aalten P, van Berckel $\mathrm{BN}$, Scheltens P: Diagnostic impact of $\left[{ }^{18} \mathrm{~F}\right]$ flutemetamol PET in early-onset dementia. Alzheimers Res Ther 2017;9:2.

25 Zannas AS, Doraiswamy PM, Shpanskaya KS, Murphy KR, Petrella JR, Burke JR, Wong TZ: Impact of ${ }^{18} \mathrm{~F}$-florbetapir PET imaging of $\beta$-amyloid neuritic plaque density on clinical decision-making. Neurocase 2014;20:466-473.

26 Johnson KA, Minoshima S, Bohnen NI, Donohoe KJ, Foster NL, Herscovitch P, Karlawish JH, Rowe CC, Hendrick S, Pappas V, Carrillo MC, Hartley DM; Amyloid Imaging Task Force of the Alzheimer's Association and Society for Nuclear Medicine and Molecular Imaging: Update on appropriate use criteria for amyloid PET imaging: dementia experts, mild cognitive impairment, and education. Amyloid Imaging Task Force of the Alzheimer's Association and Society for Nuclear Medicine and Molecular Imaging. Alzheimers Dement 2013;9:e106-e109.

27 Grundman M, Johnson KA, Lu M, Siderowf A, Dell'Agnello G, Arora AK, Skovronsky DM, Mintun MA, Pontecorvo MJ: Effect of amyloid imaging on the diagnosis and management of patients with cognitive decline: impact of appropriate use criteria. Dement Geriatr Cogn Disord 2016;41:80-92.

28 Kavirajan H, Schneider LS: Efficacy and adverse effects of cholinesterase inhibitors and memantine in vascular dementia: a meta-analysis of randomised controlled trials. Lancet Neurol 2007;6:782-792.

29 Roman GC, Salloway S, Black SE, Royall DR, Decarli C, Weiner MW, Moline M, Kumar D, Schindler R, Posner H: Randomized, placebo-controlled, clinical trial of donepezil in vascular dementia: differential effects by hippocampal size. Stroke 2010;41:1213-1221.

30 Black S, Roman GC, Geldmacher DS, Salloway S, Hecker J, Burns A, Perdomo C, Kumar D, Pratt R; Donepezil 307 Vascular Dementia Study Group: Efficacy and tolerability of donepezil in vascular dementia: positive results of a 24-week, multicenter, international, randomized, placebo-controlled clinical trial. Stroke 2003;34:2323-2330.

31 Mori E, Ikeda M, Nakagawa M, Miyagishi H, Yamaguchi H, Kosaka K: Effects of donepezil on extrapyramidal symptoms in patients with dementia with Lewy bodies: a secondary pooled analysis of two randomizedcontrolled and two open-label long-term extension studies. Dement Geriatr Cogn Disord 2015;40:186-198.

32 Doraiswamy PM, Sperling RA, Johnson K, Reiman EM, Wong TZ, Sabbagh MN, Sadowsky CH, Fleisher AS, Carpenter A, Joshi AD, Lu M, Grundman M, Mintun MA, Skovronsky DM, Pontecorvo MJ; AV45-A11 Study Group: Florbetapir F 18 amyloid PET and 36-month cognitive decline: a prospective multicenter study. Mol Psychiatry 2014;19:1044-1051.

33 Crary JF, Trojanowski JQ, Schneider JA, Abisambra JF, Abner EL, Alafuzoff I, Arnold SE, Attems J, Beach TG, Bigio EH, Cairns NJ, Dickson DW, Gearing M, Grinberg LT, Hof PR, Hyman BT, Jellinger K, Jicha GA, Kovacs GG, Knopman DS, Kofler J, Kukull WA, Mackenzie IR, Masliah E, McKee A, Montine TJ, Murray ME, Neltner JH, SantaMaria I, Seeley WW, Serrano-Pozo A, Shelanski ML, Stein T, Takao M, Thal DR, Toledo JB, Troncoso JC, Vonsattel JP, White CL 3rd, Wisniewski T, Woltjer RL, Yamada M, Nelson PT: Primary age-related tauopathy (PART): a common pathology associated with human aging. Acta Neuropathol 2014;128:755-766. 